\title{
HACIA EL DESARROLLO SOSTENIBLE. Evolución y tendencias de la política europea de medio ambiente
}

\author{
SUSANAAGUILAR FERNÁNDEZ \\ Universidad Complutense de Madrid \\ PALABRAS CLAVE ADICIONALES \\ Unión Europea, Estrategia de sostenibilidad, \\ Protección medioambiental, Governance. \\ ADDITIONAL KEYWORDS \\ European Union, Sustainable Strategies, \\ Environmental Protection, Govemance.
}

RESUMEN. En este artículo se analiza la evolución de la política medioambiental de la Unión Europea, desde sus antecedentes a mediados de los años 70 hasta su desarrollo y posterior consolidación a raíz del Acta Unica (1986), primero, y del Tratado de Maastricht (1992), más tarde. En primer lugar, el autor presenta algunas de las perspectivas teóricas que pueden ser de utilidad para analizar el desarrollo de las políticas públicas, centrándose sobre todo en el neoinstitucionalismo y la teoria de la gobernanza. En segundo lugar, se analizan las caracteristicas más relevantes de la política medioambiental europea, mostrando su naturaleza regulativa y cómo ha incorporado instrumentos económico-fiscales, basados en la voluntariedad y negociación con los grupos implicados, y en la información y educación de los ciudadanos y agentes sociales. Finalmente, el articulo expone las claves del éxito de la estrategia de desarrollo sostenible en la UE.

SUMMARY. In this article the evolution of the European environmental policy is analysed, from its origins in the seventies to its development and consolidation after the Single Act (1986) and the Maastricht Treaty (1992). Firstly, the author poses some of the most useful theoretical approaches to analyse public policies, focusing on the theory of neoinstiutionalism and the theories of govemance. Secondly, the most relevant features of the EU environmental policy are analysed, particularly its regulatory dimension and the implementation of economic selective incentives, together with efforts in information and educational campaigns aimed to both the social players and population.

\footnotetext{
' Para evitar repeticiones, en este trabajo se utilizan indistintamente los términos de desarrollo sostenible y sostenibilidad, a pesar de que no son intercambiables. Para una discusión sobre las diferencias entre los mismos, veáse Paniagua y Moyano (1998).

E-mall: susana@ceacs.march.es
}

Revista Internacional de Sociología (RIS)

Tercera Época, $N^{\circ} 35$, Mayo-Agosto, 2003, pp. 53-80. 


\section{LA EVOLUCIÓN DE LA POLÍTICA MEDIOAMBIENTAL EUROPEA: LA RELEVANCIA ACTUAL DE LAS TEORÍAS DE LA GOVERNANCE Y DEL CONSTITUCIONALISMO}

A la hora de entender el proceso de integración europea existen principalmente cuatro teorias en liza. La teoría neo-funcionalista defiende que la integración se caracteriza por ser un proceso de carácter tecnocrático en constante progreso a través del cual los Estados-nación van cediendo competencias a entes supranacionales debido a una doble dinámica: anónima, en forma de spillover, cuando estas transferencias de funciones se demuestran positivas para el manejo de los asuntos europeos y generan presiones automáticas a favor de la expansión de la competencia comunitaria a distintas políticas, y no anónima (siendo éste el elemento que la distingue de su teoría predecesora en los años 50, la funcionalista), cuando las actividades de lobby de distintos grupos de interés (principalmente empresariales) empujan en la dirección de avanzar en la construcción del mercado único. El realismo, en su vertiente de intergubernamentalismo, recalca, por el contrario, que la integración viene determinada por las negociaciones entre los Estados y que éstos persiguen mantener su capacidad de veto en asuntos que afectan (o asi son definidos por los responsables políticos) los intereses clave de la nación. La idea de una UE como gobierno (polity) en proceso de construcción, cuyos rasgos serían similares al de un sistema federal, es mantenida por la teoría constitucionalista. Dentro de esta teoría predominan los autores que recalcan el importante papel del Tribunal de Justicia Europeo (TJE) a la hora de dar rango de constitucionalidad a los tratados fundacionales y de clarificar las relaciones entre la UE, los Estados miembros y los ciudadanos a través, entre otros, de los principios de supremacía y de efecto directo, de la ley comunitaria. Finalmente, las teorías de la gobernación (governance) ${ }^{2}$ ponen el acento en la compleja naturaleza del gobiemo comunitario, el cual se desarrolla en diferentes niveles y en diferentes políticas. Aunque los Estados-nación siguen siendo actores fundamentales en el proceso, las instituciones supranacionales, los gobiernos regionales y locales y los grupos de interés (tanto de ámbito nacional como supranacional) juegan un papel muy relevante en el proceso decisorio dentro del gobierno multi-nivel (multi-level polity) que constituye la UE. Estas teorías, que han sido útiles a la hora de analizar las distintas etapas por las que ha transcurrido el proceso de

\footnotetext{
${ }^{2}$ Governance define "un proceso público no centralizado que [intenta llegar a un] equilibrio entre libertad y orden con vistas a una gestión democrática, y que incluye, pero no está limitado a, las actuaciones de los gobiemos y sus burocracias" (en Rayner, 1994: p. 5). Dentro de estas teorías destaca el trabajo de Majone, el cual ha recalcado la naturaleza regulativa de la governance europea, desempeñando la Comisión un papel regulativo (más que redistributivo) en las políticas que desarrolla, tal y como lo demuestra el caso de la política medioambiental.
} 
construcción europea, no han sido capaces de elaborar una explicación general sobre la naturaleza de la UE, pero sí han ayudado a entender mejor las distintas dinámicas que afectan a las diversas políticas sectoriales europeas. En el caso de la política medioambiental europea, por ejemplo, los progresos y retrocesos que se producen en la misma se explican, en gran medida, por la existencia de quince dinámicas políticas diferentes a nivel nacional y también, por supuesto, por la existencia de negociaciones intergubernamentales en el Consejo Europeo, dentro de lo que la variante del "liberalismo intergubernamental" de Moravcsik denomina juego de dos niveles: por un lado, en el ámbito nacional, en el que una amplia gama de actores buscan ejercer su influencia en la politica europea del Estado en el que se encuadran, y, por otro lado, en el ámbito comunitario, en el cual los gobiemos persiguen ampliar su margen de autonomía (Lynch et al., 2000). Asimismo, en el desarrollo de esta política ha sido fundamental la actuación de entes supranacionales como la Comisión, el TJE y el Parlamento Europeò (PE).

Distintos elementos de las cuatro teorias pueden, por lo tanto, ayudar a comprender la evolución de la política medioambiental europea a través de las tres etapas en las que puede dividirse:

- Los comienzos (1972-1986), en los que habia que justificar el desarrollo de la protección del medio ambiente a nivel comunitario por los posibles efectos negativos que las distintas legislaciones nacionales podían tener en la construcción del mercado común. En esta primera etapa, el neofuncionalismo, a través de los spillover que contempla (en el sentido de que las necesidades funcionales que han acompañado la configuración del mercado europeo habrían sido esenciales a la hora de tomar la decisión de elaborar una política medioambiental comunitaria), podría servir de paradigma explicativo.

- La expansión (1986-1992), cuando la política medioambiental experimenta su máximo desarrollo legislativo y es "legitimada" políticamente a través del Acta Única Europea (AUE). Es ésta una etapa en la que una mezcla de neofuncionalismo, por la importancia que adscribe a los grupos de interés en la construcción europea -y que se traduce en el impulso que hombres de negocios y corporaciones económicas imprimen al proyecto europeo y que termina plasmándose en la aprobación del AUE (Middelmas, 1995)-, y de realismo, por la indudable relevancia de los Estados miembros en su papel de arduos negociadores en la reforma de los tratados fundacionales (principalmente del Tratado de Maastricht), parece explicar los desarrollos acontecidos.

- Y, finalmente, el impasse actual (1992-), momento caracterizado por el protagonismo indiscutible de la estrategia europea de desarrollo sostenible (DS), por una mayor cautela legislativa, por más énfasis en la experimentación con distintos instrumentos que transcienden los meramente regulativos y por la entrada de nuevos actores. Las teorias de la governance, que resaltan la complejidad del juego político europeo entre muy distintos actores (no ya sólo gobiernos nacionales, que han perdido capacidad decisoria por la restricción del ejercicio 
RIS

de veto, sino regionales y locales, que se ven reforzados por el principio de la subsidiariedad, y grupos privados, a los que la Comisión consulta de forma más regular siguiendo el principio de responsabilidad compartida) y, en muy distintos niveles, resultarían el planteamiento más atractivo en esta etapa.

Junto a las teorias de la governance como modelo explicativo del momento presente, otra hipótesis de este trabajo es que el constitucionalismo debe ser integrado en una interpretación acerca del desarrollo actual y futuro de la política medioambiental europea. Y ello es así no sólo por los avances registrados a mediados del 2003 con respecto a la redacción de la futura Constitución europea, sino, principalmente, porque en el desarrollo de la protección del medio ambiente va a desempeñar un papel crucial el $\mathrm{TJE}^{3}$, debido a su mayor implicación en la tarea de hacer cumplir (enforcement) la normativa comunitaria, mientras que la Comisión, que se ha comprometido a atemperar su "activismo regulative" y a consultar de forma regular a las burocracias nacionales y a los distintos grupos de interés a la hora de elaborar nuevas propuestas, verá transformadas sus funciones. Además, es la propia Comisión la que parece interesada en otorgar un papel más relevante al TJE, como lo prueba el hecho de que haya sido esta institución la que ha pedido al Tribunal que anule la decisión marco, adoptada por el Consejo Europeo a comienzos del 2003, relativa a la protección medioambiental a través del derecho penal, debido a que, en su opinión, una directiva, basada en el artículo 175 del Tratado de la Unión Europea (como base legal generalmente utilizada para desarrollar la normativa medioambiental), proporcionaría una mejor garantía a este objetivo gracias a que se transpondría al ordenamiento interno por los Estados miembros y estaría sujeta a control por esta instancia judicial. Asimismo, otro de los rasgos de la política medioambiental europea en nuestros dias es que los Estados miembros, aunque "fiscalizados" más estrechamente por el TJE, que ha ganado poderes de sanción, gozan de un mayor grado de laxitud a la hora de aplicar, con los procedimientos y técnicas que consideren más adecuados, la normativa comunitaria ${ }^{4}$, por la prioridad que se otorga a lo que podría denominarse

\footnotetext{
${ }^{3}$ El papel crucial desempeñados por el tribunal ha sido señalado, entre otros, por Snyder, que, en relación con la aprobación de legislación comunitaria en forma de nomas aduaneras, afirma que el TJE contribuye a la europeización cuando, ante la ausencia de normativa, sustituye al menos provisionalmente al legislador a través de la armonización de las reglas del comercio internacional (Snyder, 1999).

'Esta mayor laxitud se refiere al procedimiento de aplicación de la norma, y no a la norma en sí misma. Por ello, los países que se integren en la UE, dentro de la cuarta ampliación, tendrán ineludiblemente que aceptar el acquis communautaire al tiempo que se les privaráa de la posibilidad de acogerse a opt-outs. Otro tema es el de los plazos de aplicación de la legislación medioambiental, ya que, ante el deficiente estado de su medio ambiente y dada su crítica situación económica, algunos gobiernos post-comunistas están manejando horizontes temporales largos, de hasta catorce años, a la hora de negociar su transposición.
} 
"directivas marco de nueva generación" y, sobre todo, a la estrategia europea de DS, que se caracteriza por no apostar por un único modelo de sostenibilidad y por la imprecisión del concepto ${ }^{6}$. Actualmente, la elaboración de estrategias de desarrollo sostenible, completamente dispares por parte de los distintos países comunitarios, que contribuyen, en muchos casos, a diluir y desvirtuar la política medioambiental de concretos y rigurosos estándares bajo planteamientos genéricos e imprecisos de sostenibilidad, asi como la naturaleza jurídicamente no vinculante de las mismas, que imposibilita que la Comisión y en última instancia el TJE, a diferencia de lo que ocurre con la política medioambiental, controlen tanto el contenido como el cumplimiento de dichas estrategias, explican el porqué de la elección del término impasse para caracterizar el período presente. Es decir, el impasse define una situación de incertidumbre con respecto a los derroteros por los que vaya a discurrir la política medioambiental lo cual se explica porque, junto a la existencia de elementos que parecen presagiar una ralentización en el avance de la misma (la existencia de directivas marco que permite un mayor margen de maniobra a los gobiernos en cuanto a su aplicación, y el triunfo de la sostenibilidad, que subsume en muchos casos la política medioambiental en estrategias nacionales predominantemente vagas e imprecisas), aparecen también indicios que apuntan en la dirección contraria: desde el reforzamiento del TJE como "fiscalía medioambiental" y la ampliación del principio de decisión por mayoria, que recoge el borrador de Constitución europea, a temas con cruciales repercusiones sobre el medio ambiente, como la energía, que todavía estaban sujetos a la unanimidad.

Un breve repaso a los elementos (las directivas marco y la estrategia europea de DS) que parecen presagiar este retroceso en la política medioambiental europea ayudará a aclarar las dudas que suscita el momento actual en relación con su futuro desarrollo. Tal vez el mejor ejemplo de las nuevas directivas marco sea el de la Directiva 2000/60 de aguas. La legislación europea sobre aguas comenzó tempranamente, en la década de los años 70 , estableciendo estándares para los

${ }^{5}$ El informe Brundtland argumenta que no existe un único modelo (blueprint) de DS, ya que las condiciones económicas, sociales y ecológicas varían enormemente entre los países, y, por ello, cada Estado deberá resolver las implicaciones especificas del DS para su caso concreto. De esta forma, "se deja en manos de los decisores políticos la tarea de traducir a la práctica lo que de hecho son declaraciones politicas simbólicas de gran generalidad" (Baker ef al., 1997: p. 4). Esta necesidad del DS de "acomodarse" a las circunstancias específicas del pais en cuestión se encuentra constantemente en la estrategia española de desarrollo sostenible (Aguilar, 2003a).

6 Una detallada discusión de las dimensiones y de la naturaleza polisémica del concepto de DS se encuentra en Paniagua y Moyano (1998). 
RIS

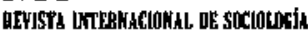

N" 35, Mayo-Agosta, 20003

rios y lagos que suministraban agua potable (1975), y culminó en 1980, al proponer objetivos de calidad obligatorios para este mismo uso, así como para la vida piscícola, moluscos, aguas de baño y subterráneas. Tras el encuentro ministerial para tratar los problemas hídricos en la UE, celebrado en Frankfurt en 1988, comienza una segunda fase, en la que se identifican una serie de mejoras que pueden acometerse, así como algunas de las lagunas a cubrir, y que se plasman en la adopción, en 1991, de la Directiva para el tratamiento de las aguas residuales urbanas y de la Directiva de nitratos. A mediados de los años noventa se produce de nuevo un replanteamiento crítico de la politica de aguas, basado en la necesidad de adoptar un enfoque más global sobre el tema. Lo que se ha venido en denominar nueva Política Europea del Agua se caracteriza principalmente por fomentar un proceso de consulta abierto con las partes interesadas (autoridades locales y regionales, regantes y usuarios, y ONGs) y una aproximación holistica al problema de la calidad del medio hídrico (prueba de ello es la aprobación, en 1996, de la Directiva para el control integrado y preventivo de la contaminación). La Directiva marco del año 2000 , en concreto, parte de un supuesto crucial: la existencia de una política fragmentada, en términos tanto de objetivos como de medios, que exige una simplificación (streamlining) normativa. Para ello, sustituye siete Directivas de la primera etapa de la política de aguas, que son incorporadas a la Directiva marco, permitiéndose que sean derogadas. Además, otro rasgo fundamental de esta Directiva, más allá de su apuesta por la cuenca hidrográfica como unidad de gestión o por combinar los enfoques de calidad (o inmisión) y los de emisión, es la mayor discrecionalidad que permite a los Estados miembros a la hora de poner en práctica esta política de aguas, puesto que la aplicación de la directiva será el resultado de un amplio proceso participativo, que implicará necesariamente equilibrar los intereses contrapuestos de los distintos grupos, que, a su vez, diferirán dependiendo del pais en cuestión. Asimismo, la Directiva recoge abundantes excepciones a la norma: cuando se habla, por ejemplo, de utilizar mecanismos de precios que reflejen los costes de la política, se admiten excepciones en zonas poco desarrolladas económicamente o en situaciones en las que el servicio tenga que prestarse a precios razonables; también se recoge que, ante la imposibilidad de determinar estándares absolutos para la calidad biológica, debido a la variabilidad ecológica que caracteriza a la UE, los Estados miembros deberán interpretar los procedimientos destinados a alcanzar tal calidad de forma diferente (aunque con consistencia, de forma que se garantice la comparabilidad de los resultados). Pero, más importante aún que este nuevo desarrollo en la política medioambiental, que se traduce en Directivas marco más globales, pero también más genéricas, así como en una reducción de la normativa existente, es, como ya se apuntó anteriormente, el predominio del DS como estrategia omnicomprensiva que tiende, incluso, a subsumir la política de medio ambiente dentro del programa de la sostenibilidad. No en vano, tras la evaluación del $5^{\circ} \mathrm{PAM}$, que comienza a finales de 1998, un número cada vez mayor de actores coincide en afimar que 
los futuros programas deberán centrarse más en la política de DS y menos en una política medioambiental de objetivos estrechos y limitados?.

Una de las características básicas de lo que podría denominarse proyecto europeo medioambiental es, en estos momentos, la relevancia indiscutible en la agenda europea del DS, que, postulando la compatibilidad entre crecimiento económico, cohesión social y protección del medio ambiente, ha desbancado por completo concepciones anteriores que, o bien propugnaban la congelación del crecimiento económico como forma de afrontar el deterioro ecológico, o bien recalcaban que la defensa de la calidad medioambiental podía estar por encima de la libertad de circulación de mercancías, uno de los principios básicos del mercado común (tal y como sentenció el TJE en el célebre caso de las "botellas danesas"). La indefinición que aún rodea al concepto de DS, asi como la pretendida armonia que en éste subyace a la hora de atender, al mismo tiempo, a necesidades económicas, sociales y mediombientales, ayudan a entender, entre otras razones, el porqué de su triunfo político a nivel comunitario. Por otra parte, el indudable valor que el concepto atribuye a la participación social y a la profundización de los mecanismos democráticos de consulta como medio para conseguir el DS y como fin en sí mismo de la sostenibilidad, fomentará la entrada en escena de nuevos actores y la consiguiente complejización del panorama medioambiental europeo, con lo cual la necesidad de recurrir a teorías de governance se hará aún más acuciante.

\section{Caracterización de la POLÍtica europea de MEdio AMBIENTE}

La política de protección del medio ambiente es una de las más populares e incuestionadas de la UE, y también una de las de mayor éxito (Collier, en Grant et al., 2000). Con relativa independencia del ciclo, euro-optimista o euro-pesimista, por el que esté pasando el proyecto comunitario, los Eurobarómetros señalan que los europeos otorgan gran legitimidad a la actuación europea en medio ambiente: a lo largo de los años, una gran mayoría de entrevistados opina que la conservación del medio ambiente es un problema urgente y expresa su insatisfacción con las medidas tomadas por las autoridades nacionales a este respecto ${ }^{8}$. Quizás sea ésta una de las razones por las cuales la mayoria de los Estados miembros han sido relativamente poco reticentes a ceder autoridad a Bruselas en este campo.

\footnotetext{
'En comparación con el DS, "la política medioambiental (seria) un área politica de propio derecho que podría beneficiarse de un programa (de DS) con objetivos claros y factibles" (www.rec.org/REC/Bulletin).

${ }^{8}$ En 1996 , por ejemplo, las encuestas señalaban que más de un $69 \%$ de los ciudadanos europeos creían que la UE debía jugar un papel más importante que los gobiemos nacionales en la protección del medio ambiente (en www.europeanmovement.ie).
} 
RIS

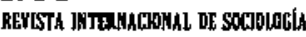

N. 35, Mayo-4gasto, 2003

SUSANA ACULLAR FERNÁNDEL

A pesar de su popularidad, esta politica es conflictiva, debido, entre otras razones, a que "la UE es la única institución en el mundo que [detenta] el poder de imponer obligaciones medioambientales vinculantes a Estados soberanos" (Bennet et al., 1989: 11). Como prueba de este poder no hay más que recordar que se calcula que, en tomo al $90 \%$ de la legislación medioambiental que se aplica en España proviene de Bruselas, al tiempo que se ha constatado también que la actividad de los grupos de presión en política de medio ambiente ha ido desplazándose gradualmente desde la esfera nacional a la comunitaria. Este poder, junto al importante gasto presupuestario que apareja el cumplimiento de la normativa comunitaria, explica el enorme interés por influir en la toma de decisiones que demuestran los Estados miembros. En este proceso de ejercicio de influencia y presión, las disputas acerca de prioridades y contribución a, y reparto de, fondos son lógicamente constantes. Estas diferencias reflejan, en gran medida, la disparidad de criterios que existe entre los países comunitarios más desarrollados del Centro y Norte de Europa y los menos desarrollados del Sur: los primeros suelen perseguir una protección rigurosa y costosa del medio ambiente, centrada en la armonización de estrictas medidas de control de la contaminación industrial, mientras que los segundos, apoyándose, entre otras razones, en la heterogeneidad de los ecosistemas europeos, propugnan un mayor grado de discrecionalidad o laxitud con respecto a los estándares e instrumentos políticos a aplicar (tema en el que coinciden con el Reino Unido) y buscan reorientar la agenda europea hacia problemas de distinta índole, como la erosión del suelo y la desertificación. La tensión Norte-Sur encuentra un magnífico ejemplo en la polémica que protagonizaron España y Alemania en tomo a la conveniencia o no de crear un fondo de cohesión que contribuyera a sufragar acciones de protección del medio ambiente en las negociaciones que rodearon el Tratado de Maastricht (Aguilar, 1997b).

Tradicionalmente, los países prósperos han condicionado en mayor medida que los del Sur la agenda medioambiental de la UE, pero este sesgo se ha visto gradualmente compensado por una política más activa y ambiciosa de Estados que, como España, han empezado a comprender que no es bueno permitir que el protagonismo recaiga siempre en la famosa troika (principalmente Holanda, junto con Dinamarca y Alemania) o, más recientemente, en los países nórdicos que ampliaron la Comunidad en 1995 (Aguilar, 1998).

La existencia de arduas negociaciones entre las distintas partes que acompaña a la política de medio ambiente no ha impedido que ésta haya sido una de las menos cuestionadas en la UE. Prueba de ello es que las primeras medidas de corte medioambiental no sólo fueron adoptadas sin una clara base legal, sino que se aprobaron en plena etapa de euro-esclerosis. Esto no supuso un obstáculo para que la Comisión (con la aquiescencia de la mayoría de los Estados miembros) fuera ampliando su jurisdicción hacia temas cada vez más diversos. No es de extrañar, por lo tanto, que el Tribunal de Auditores haya señalado que, "a lo largo de los años, la protección del medio ambiente se ha convertido gradualmente en un rasgo esencial de la actividad comunitaria" (en Sbragia, 1993:p. 339). Constituye así un 
hecho de gran relevancia que, a pesar de la inexistencia de una justificación legal inicial, se haya desarrollado una política medioambiental europea y que ésta haya alcanzado, además, un grado de progreso del que otras políticas indudablemente comunitarias (como la de transporte o energia) no disfrutan. Además, la protección del medio ambiente ha funcionado como una poderosa fuerza en favor de la integración europea y, por ello, podría ser peligroso que en el futuro próximo se redujeran las competencias de la Comunidad en este campo mediante una estricta aplicación del principio de subsidiariedad.

La protección del medio ambiente es claramente un ejemplo de política regulativa. Es decir, a diferencia de politicas distributivas, como la PAC, o redistributivas, la protección del medio ambiente no genera "clientelas o beneficiarios que se pronuncien a favor de la continuación y desarrollo de la política" (Grant et al., 2000: 2). La regulación (o los instrumentos de tipo command-and-control) es, por lo tanto, el principal mecanismo a la hora de ejercer un "poder medioambiental" por parte de la UE. La directiva, claramente un instrumento regulativo, ha sido elegida para desarrollar esta política por dos motivos principales: en primer lugar, porque es de obligado cumplimiento en cuanto a sus fines (al igual que el reglamento) y produce, o intenta producir, una relativa amonización de forma que se evite tanto una desigual distribución del gasto medioambiental, como una distorsión del principio de libre circulación de mercancías; en segundo lugar, porque, como es discrecional en cuanto a los medios para el cumplimiento de los fines (a diferencia del reglamento), posibilita que los países elijan las estrategias que consideren más adecuadas y permite una cierta flexibilidad en la realización de la política. En este sentido, la directiva refleja una realidad según la cual la Comisión, careciendo de los medios necesarios para asegurar el cumplimiento de las obligaciones medioambientales, se ve obligada a aceptar las diferentes capacidades administrativas y voluntades politicas de los Estados miembros. La directiva consigue, así, un cierto compromiso entre dos tipos de paises: los tradicionalmente comprometidos con una politica rigurosa (la troika y, más recientemente, Suecia, Finlandia y Austria), que buscan un determinado grado de homogeneización de la misma que disminuya el riesgo de desventajas competitivas para sus industrias y satisfaga la sensibilidad ecológica de sus electorados, y aquellos otros que, mostrando otras prioridades (el Sur de Europa, en líneas generales), o cuestionando su extensión hacia nuevos ámbitos, así como su énfasis armonizador (Reino Unido), persiguen llevarla a cabo con sus propias estrategias o con un mayor grado de laxitud.

A pesar de su naturaleza básicamente regulativa, la política medioambiental ha ido incorporando nuevos instrumentos politicos, tanto de tipo económicofiscal, como basados en la voluntariedad y la negociación con los target-groups, y centrados en la información y educación de los ciudadanos y agentes sociales. "Dentro de este laboratorio político (...) la discusión sobre los instrumentos más adecuados para resolver el deterioro ecológico sígue todavía su curso. Aunque la 
elección del instrumento depende, evidentemente, del problema en cuestión, en la práctica parece imponerse progresivamente una combinación de los mismos (...). La experimentación y la combinación de elementos de estado y mercado es pues constante, ya que en política medioambiental, en mayor medida que en otras políticas públicas, las recetas mágicas no existen" (Aguilar, 1997b: 117). Junto a esta experimentación, otro rasgo de esta política es que constituye un área de gestión relativamente nueva en la que predomina el expertise técnico-científico (base precisamente de la abundante regulación en este campo), y que es ejemplo del ímpetu comunitario en la esfera internacional (actualmente, la UE es parte signataria de más de treinta acuerdos medioambientales multilaterales) (Grant $e t$ al., 2000).

\section{ANTECEDENTES Y DESARROLLO}

El comienzo del "activismo medioambiental" de la UE en los años setenta se explica gracias a las presiones que dimanaron de la Conferencia Internacional sobre Medio Ambiente celebrada en Estocolmo en 1972. Además, los informes que por entonces preparaba el Club de Roma impresionaron vivamente al Vicepresidente de la Comisión, Sicco Mansholt, que envió una carta al Presidente de esta institución para pedir un cambio radical en la política económica comunitaria (Wurzel, en Lodge, 1994). Esta petición resultó meramente en la adopción por el Consejo, del Acuerdo de Información e Inacción (standstill), de 1973, según el cual los Estados miembros acordaban informar a la Comisión sobre aquellos proyectos de ley medioambientales que afectaran directamente al mercado interno, de forma que esta institución pudiera, en un plazo determinado, presentar propuestas al Consejo sobre la posible adopción de medidas similares a nivel comunitario. Este acuerdo reconocía, sin embargo, que la armonización no debia ser obstáculo para que se adoptaran por parte de los gobiernos las acciones necesarias para proteger el entomo, y aceptaba que los Estados miembros estuvieran autorizados, de forma excepcional, a aplicar inmediatamente determinadas medidas si éstas eran necesarias para la protección de la salud o del medio ambiente.

Así pues, es en 1972 cuando los Jefes de Estado y de Gobiemo de la UE deciden desarrollar una política medioambiental. Las únicas referencias en los tratados fundacionales que podían justificarla eran, dentro del Tratado de Roma de 1957, los artículos 100 (el Consejo puede adoptar, de forma unánime y a propuesta de la Comisión, directivas para la aproximación de las disposiciones legales de los Estados miembros cuando éstas incidan directamente en el establecimiento o funcionamiento del mercado común) y 235 (posibilidad de que el Consejo, también unánimemente y siguiendo a la Comisión, adopte las disposiciones pertinentes que conduzcan a la aprobación de una acción cuyo fin sea el logro de alguno de los objetivos de la Comunidad, a pesar de que para ello no se haya previsto la 
potestad necesaria). No existía, por lo tanto, una clara base jurídica que legitimara esta política, lo cual no impidió al Consejo Europeo encargar a la Comisión la elaboración de un Programa de Acción Medioambiental (PAM) en 1972, tras declarar, en la Conferencia Internacional sobre Medio Ambiente y Desarrollo celebrada en Estocolmo, que la expansión económica no era un fin en sí mismo. Este primer PAM (1973-1976), al que han seguido otros cinco, representa un hito en la actuación de la UE, ya que las acciones de este tipo que habían existido con anterioridad se habían vinculado, explícitamente, al intento de evitar distorsiones de la competencia. No cabe duda de que en la decisión de elaborarlos influyó tanto la creciente sensibilidad ecológica de la sociedad, como la constatación de la inutilidad de tratar determinados problemas medioambientales desde un prisma meramente nacional.

El análisis de los sucesivos PAM y directivas refleja una evolución en la política medioambiental desde una primera etapa, en la que predominaron las medidas reactivas y de tipo "curatorio" (que apostaban por tecnologias end-ofpipe) y en la que la preocupación principal estribaba en armonizar la legislación medioambiental por las negativas repercusiones económico-comerciales que la disparidad de ordenamientos nacionales podía entrañar, a otra segunda y tercera etapas, más vinculadas a medidas de tipo preventivo y articuladas en torno a Ia protección del medio ambiente como bien en sí mismo. En este sentido, se constata un tono aseverativo en los sucesivos PAM, los cuales van gradualmente considerando la protección del entomo como política comunitaria de facto que no necesita ser justificada. En esta línea, la Comisión extiende progresivamente su ámbito competencial (ya el segundo PAM, por ejemplo, recoge una directiva que protege los hábitats de 142 especies de pájaros en peligro de extínción, tema sobre el cual Bruselas no había legislado previamente). Además, los PAM adquieren un carácter cada vez más ambicioso, al intentar modificar los malos hábitos político-administrativos o las inercias que lastran la eficacia de las politicas públicas de medio ambiente (el tercer PAM, en este sentido, defiende ya el principio de integración o la necesidad de incorporar el componente medioambiental en otras políticas sectoriales, así como la necesidad de prestar más atención al problema del cumplimiento, o enforcement, de las políticas). Asimismo, la protección del medio ambiente es una política abierta a la experimentación, pues el cuarto PAM, entre otras cosas, incorpora temas nuevos como el de la biotecnologia, la seguridad nuclear, la contaminación del suelo y la conveniencia de utilizar instrumentos económicos junto con el enfoque regulativo tradicional. El anterior énfasis acerca de la necesidad de cumplir la política se refuerza aún más y se combina con la petición de avanzar en la investigación y recogida de información en esta materia. El quinto PAM se centra en los sectores económicos con incidencias negativas sobre el entorno (transporte, energía, industria, agricultura y turismo), incide en el principio de responsabilidad compartida desde un enfoque participativo (bottomup) y no impuesto desde arriba (top-down) y suscribe el concepto de DS de modo 
"que se transforme el sistema económico global [para] satisfacer las necesidades del presente sin comprometer la capacidad de las futuras generaciones de satisfacer las suyas propias". Repite, por último, la necesidad de integrar el medio ambiente en otras políticas sectoriales, ampliar el tipo de instrumentos que se aplican en este campo, mejorar la aplicación y el cumplimiento de la legislación ya existente, y recalca la urgencia de cambiar actitudes y pautas de consumo y producción. El último PAM, titulado "Medio Ambiente 2010: Nuestro Futuro, Nuestra Elección", ha sido el elaborado por la comisión en el año 2001; en el mismo se resalta la importancia de los temas procedimentales (por ejemplo, la necesidad de aplicar definitivamente el principio de integración ${ }^{9}$ ) a la hora de avanzar hacia el DS; de la cooperación con el mercado, a través de los grupos de interés empresarial y de consumidores, de forma que se produzcan pautas de producción y consumo sostenibles; de la mejora del acceso de los ciúdadanos a una información de calidad sobre el medio ambiente; y de las decisiones que se toman en el seno de los Estados con respecto a temas de planificación urbana y gestión territorial, asuntos en los que la Comunidad puede ser de gran ayuda a través de la promoción de políticas de best practice y de reparto de fondos estructurales. Asimismo, se vuelve a insistir en la necesidad de mejorar la aplicación de la legislación existente, señalando que la acción legal que se emprenda a través del TJE debe combinarse con una política de información pública que siga el lema "name, fame and shame", que consiste en dar a conocer rankings en los que se comparen los rendimientos medioambientales de los distintos paises miembros ${ }^{10}$.

Los dos últimos PAM siguen la tendencia iniciada tras la Cumbre de la Tierra, celebrada en Río de Janeiro en 1992, según la cual la atención se desplaza desde la política medioambiental a la necesidad de conseguir el desarrollo económico en un contexto de sostenibilidad medioambiental. Por ello, y a diferencia de otros autores que ađscriben a la evolución de los PAM un rasgo meramente incrementalista (Baker et al., 1997), aquí se defiende que, de su comparación, se pueden deducir importantes cambios políticos de planteamiento con respecto a lo que se entiende por política medioambiental comunitaria y al papel que la UE, los gobiernos y los actores sociales deben jugar en la misma.

9 Sobre el principio de integración medioambiental y su relación con el DS, veáse Aguilar (2003b).

${ }^{10}$ La Comisaria de Medio Ambiente, Margot Wallström, señaló que el primer ranking medioambiental sería publicado en la primavera del 2003, como parte integral de una politica de DS en la UE, y que medirfa el consumo de energía y las acciones tomadas para afrontar el cambio climático. 


\section{Del Acta Única Europea al Tratado de Maastricht}

La expansión de la política medioambiental comunitaria está indudablemente relacionada con la reforma de los tratados fundacionales 0 , principalmente, con la aprobación del Acta Única Europea (AUE), en 1986, y del Tratađo de la Únión Europea (o Tratado de Maastricht), en 1992. El AUE proporciona reconocimiento legal explícito a esta política (se introduce un Título VII en los tratados fundacionales, cuyo artículo 130r recoge, a través de sus cinco apartados, lo que será la filosofia comunitaria en este tema), y reforma su proceso decisorio, otorgando un mayor peso al PE y ampliando los supuestos de aplicación del mecanismo de voto por mayoría cualificada en el Consejo, aunque la unanimidad sigue siendo la regla. Para impedir, sin embargo, que el principio de unanimidad pueda ser utilizado para bloquear propuestas medioambientales avanzadas, se permite el mantenimiento y la adopción de medidas rigurosas por parte de los Estados miembros que así lo deseen (art.130t), aunque éstas no deberán implicar trabas al libre comercio (art.100a(4)). Para satisfacer, igualmente, a los paises "ecológicamente comprometidos", se acepta que la Comisión, en sus propuestas referentes a la aproximación de las legislaciones nacionales, se base en un nivel de protección medioambiental elevado (art.100a(3)). Aún así, esta cláusula fue considerada insuficiente por paises como Alemania y Dinamarca que presionaron para que se incluyera el artículo $100 \mathrm{a}(4)$, según el cual los Estados miembros, tras la adopción por el Consejo de una medida de armonización por mayoría cualificada, pueden aplicar sus disposiciones nacionales si lo justifican razones de protección del medio ambiente. Indudablemente, la prioridad de los temas medioambientales en la agenda comunitaria es mayor desde la aprobación del AUE, y, por ello, el periódico norteamericano, Financial Times, aseveraba en 1990: "la politica medioambiental ... ocupa hoy una posición en el centro mismo del escenario de la CE" (en Sbragia, 1991). Sin embargo, a pesar de que en líneas generales el AUE contribuyó al avance de la política medioambiental, en su momento se expresaron dudas sobre la potencialidad del principio de subsidiariedad a la hora de restringir el margen de discrecionalidad de la Comisión en esta política.

El Tratado de Maastricht, por otra parte, ha ido más allá que el AUE en cuanto al progreso de la política medioambiental. Este tratado afirma que la consecución del crecimiento económico deberá ser siempre sostenible y no perjudicial para el medio ambiente (art.2), y que la protección de éste constituye una tarea común que tendrá que ajustarse al principio de precaución (art.3). La innovación principal del mismo es que convierte el mecanismo de voto por mayoria cualificada, con unas pocas excepciones, en la regla en la toma de decisiones medioambientales (art.130s), al tiempo que vincula esta política al mecanismo de cooperación con el PE. La unanimidad queda reservada a asuntos de naturaleza fiscal (impuestos ecológicos), o relacionados con la planificación y el urbanismo, los recursos acuíferos, y los temas energéticos. La decisión de situar el principio de subsidiariedad fuera del 
ámbito de la política medioambiental, tal y como se hace en Maastricht, ha sido interpretada, sin embargo, como un intento por aumentar su importancia, lo cual podría tener repercusiones negativas para esta área de gestión.

El progreso de la política medioambiental no está vinculado únicamente a la reforma de los tratados fundacionales, o al "impetu verde" de determinados Estados miembros en ciertas materias, sino también al papel del TJE y del PE. El TJE ha apoyado siempre la expansión de los poderes de la UE en la politica medioambiental en línea con el "activismo judicial" que también ha exhibido con respecto a otras politicas. A pesar de que en sus primeras sentencias el TJE vinculó la política a la necesidad de armonizar medidas nacionales de forma que se eliminaran barreras comerciales, a mediados de los años setenta defendió que la protección del medio ambiente constituía uno de los objetivos esenciales de la Comunidad. Una vez que el tema medioambiental fue formalizado por el AUE, el Tribunal favoreció una interpretación amplia del artículo 100a, tal y como se recogió, por ejemplo, en la sentencia sobre la industria del titanio (caso 300/89). Desde mediados de los años ochenta, el TJE ha señalado que la protección del medio ambiente puede estar por encima incluso de la consecución del mercado único, tal y como ocurrió con la sentencia de 1985, que reconocía la legitimidad del gobierno francés para crear sistemas restrictivos de recogida y tratamiento de aceites usados, o con el caso de las "botellas danesas" (caso 302/86), en el que el tribunal validó el sistema danés de depósito y retomo de envases que establecía determinados requisitos a cumplir por los productores y distribuidores de cervezas y refrescos (dentro de la doctrina de la "integración diversificada"). Este caso marcó un hito, ya que la Comisión habia señalado, antes de que se conociera la sentencia, la necesidad de determinar "hasta qué punto la preocupación por la protección del medio ambiente [tenía] prioridad sobre el principio del mercado común sin fronteras, puesto que [existía] el riesgo de que (determinados) Estados miembros pudieran buscar refugio detrás de argumentos ecológicos para evitar abrir sus mercados" (Koppen, 1992: p. 20). Frente a estas sentencias favorables al medio ambiente, el principio de reconocimiento mutuo (elaborado a raíz del caso Cassis de Dijon) podría tener repercusiones adversas para el mismo. La liberalización, o des-regulación, que acompaña a este principio tiene dos consecuencias diferentes: por un lado, simplifica el largo y costoso proceso de armonización que intenta establecer estándares europeos uniformes y detallados, mientras que, por otro lado, puede facilitar la entrada de bienes de "baja calidad ecológica" en paises con niveles estrictos de protección del medio ambiente.

Junto al TJE como fuerza promotora de la protección del medio ambiente se encuentra el PE, que ha apoyado tanto la ampliación de la jurisdicción comunitaria, como legitimado las actuaciones de la UE en este campo. Ya en 1972, el Parlamento invitaba a la Comisión a examinar si los tratados fundacionales debían ser reformados para incorporar apartados medioambientales, mientras que, un año más tarde, establecía en su seno un comité específico para tratar este tema. Asimismo, propuso que se creara una Agencia Europea para coordinar y 
elaborar estudios en esta política, y, en 1983, siguiendo una sugerencia del TJE, señaló que el Tratado de la CEE debería ser modificado de forma que los Estados miembros que no ejecutaran las sentencias del Tribunal fueran sancionados más efectivamente. Su influencia, a diferencia de la de esta última institución, ha sido más simbólica que real. Un ejemplo de ello es que ninguna de las dos propuestas que el PE había acordado con la Comisión en el seno de la Conferencia Intergubernamental (CIG) que negociaba el AUE fue aprobada ${ }^{11}$. El papel de la cárnara sí fue, sin embargo, significativo cuando consiguió que la Comisión publicara, a partir de una petición de 1983, informes anuales sobre la aplicación de la politica medioambiental. Las propuestas del PE han sido de forma constante más "verdes" y radicales que las de las otras instituciones comunitarias: en el caso de la DIR $89 / 458$ sobre emisiones de vehículos de pequeña cilindrada, la cámara pidió estándares más estrictos; en la directiva sobre grandes centrales térmicas se propusieron plazos de adaptación más cortos; y en la directiva sobre información medioambiental, se presionó para que existieran menos excepciones en cuanto al acceso a la misma. Las preguntas parlamentarias son utilizadas cada vez más como un medio indirecto de iniciar procedimientos contra los Estados miembros que incumplen sus obligaciones medioambientales: en 1989, la Comisión reconoció explícitamente la labor del PE en cuanto a control de la legislación comunitaria se refiere a través de estas preguntas. Además, el Parlamento ha pedido que se conceda mayor publicidad a los procedimientos de infracción abiertos contra los países; ha animado a la ciudadanía a elevar peticiones a la cámara en caso de que sus gobiernos no cumplan la legislación de la UE; y ha solicitado a la Comisión que se la permita examinar las quejas que recibe de los ciudadanos. A pesar de todo, sólo puede hablarse de cierto éxito en su estrategia de reforzamiento de la política medioambiental si el Consejo está dividido sobre el asunto en cuestión y si la cámara actúa de común acuerdo con la Comisión algo que sucede con frecuencia con respecto a la DG XI, Dirección General encargada de este tema. La ampliación de las competencias del PE, que las sucesivas reformas de los tratados fundacionales han contemplado, así como el fortalecimiento de esta institución (que, entre otras cosas, podria llegar a controlar el $85 \%$ del presupuesto de la UE) que recoge el proyecto de Constitución europea, presentado en mayo del 2003, contribuirán indudablemente al éxito de esta estrategia.

\footnotetext{
"Frente a la propuesta de adoptar el mecanismo de voto por mayoria cualificada en la política medioambiental, el AUE mantuvo la unanimidad; y frente a la propuesta de amonizar las leyes nacionales según el más alto nivel de protección, el texto recoge una mera mención a un nivel elevado.
} 
RIS

REVISTA MTEAMUCOYYL DE SOCOLACIA

NP 35, May0-dgosto, 2003

SLSANA AGULLAR FERNANDEZ

\section{De Maastricht a Amsterdam}

El proceso de reforma que comenzó con el AUE y culminó con el Tratado de Maastricht tuvo como hitos principales del proyecto europeo la práctica finalización del Mercado Único Europeo y la puesta en marcha de la Unión Económica y Monetaria (UEM). El período post-Maastricht, sin embargo, se caracteriza por la pérdida de empuje de este proyecto, o la "erosión de la confianza y el incrementalismo" (Lynch et al., 2000: p. 235). El reformismo del periodo anterior liderado por elites políticas provocó un cierto rechazo por parte de determinados sectores de la ciudadanía que dificultó la continuación del mismo. La dificil ratificación del Tratado de Maastricht (rechazado en el referéndum danés de 1992, aprobado por un estrecho margen en la consulta realizada en Francia, debatido críticamente en el Parlamento británico y aprobado, con cautelas, por el Tribunal Constitucional alemán) desató una crisis de confianza en la UE que se reflejó, entre otras cosas, en una apuesta decidida de la nueva Comisión, presidida por Santer, por consolidar lo ya conseguido, abandonando veleidades de ambición política y activismo regulatorio (algo que ya había sido defendido, dentro del nuevo clima político de predominio de principios como el de subsidiariedad y el des-regulación, por el anterior Presidente de la Comisión, Delors, desde finales de los años 80). Las encuestas reflejaban, además, un menor apoyo a la integración europea como resultado de las políticas restrictivas de gasto público que acompañaban a la UEM. Esta nueva etapa de euroescepticismo se manifestó, asimismo, en la aparición o consolidación de partidos anti-Europa, y en la acentuación del disenso en tomo al proyecto europeo en el seno de formaciones como los conservadores británicos y los neo-gaullistas franceses. Es en este contexto en el que se aprueba el Tratado de Amsterdam de 1997, criticado principalmente por no ofrecer la reforma institucional necesaria que facilite la futura ampliación de la $\mathrm{UE}^{12}$, aunque haya aumentado la relevancia del $\mathrm{PE}$ en el proceso legislativo, ampliado el uso del voto por mayoría cualificada y åadido transparencia al proceso decisorio, mediante, entre otras cosas, un mejor trasvase de información a los parlamentos nacionales.

En política medioambiental, el nuevo tratado entroniza de forma explícita el principio de DS como uno de los objetivos primordiales de la UE. La integración de la protección medioambiental en todas las políticas sectoriales (particularmente en las áreas de transporte y agricultura) es otro de los elementos a reseñar. También se señala que la Comisión se compromete a preparar estudios de evaluación de impacto medioambiental cuando elabore propuestas que tengan significativas consecuencias sobre el entorno físico. Finalmente, a los Estados miembros se les

\footnotetext{
${ }^{12}$ El problema de la futura ampliación de la UE a los Estados asociados fue resuelto en el Tratado de Niza, firmado en el 2001, y que entró en vigor dos afios más tarde.
} 
permite seguir manteniendo el derecho a tener estándares medioambientales más altos, siempre y cuando no constituyan barreras al comercio ${ }^{13}$.

El período post-Maastricht está vinculado estrechamente al principio de subsidiariedad, aunque el hecho de que el Tratado de Amsterdam establezca las reglas para su aplicación en un protocolo no ha sido interpretado como una extensión del mismo. A pesar de ello, la Comisión está intentando disipar las dudas que rodean la legitimidad de su actuación en la política medioambiental mediante un mayor énfasis en el diálogo y la cooperación entre las instituciones comunitarias, los Estados miembros, las industrias, y los ciudadanos. Esta institución sopesa ahora más detenidamente la conveniencia o no de proponer nueva legislación medioambiental y se ha propuesto reducir la actividad regulativa en este ámbito. En la actualidad, por lo tanto, la mayoria de esta actividad se vincula a la actualización de la legislación existente o al desarrollo de directivas marco, al tiempo que, en el proceso de preparación de directivas, se han aumentado las consultas con distintos grupos y se ha intensificado el papel del PE. No sólo la subsidiariedad, sino también sonados fracasos políticos, como el intento fallido por parte de la Comisión de adoptar un impuesto energético, están detrás de esta mayor cautela (Grant et al., 2000).

\section{HIPOTÉTICOS ESCENARIOS DE FUTURO}

La interpretación sobre los nuevos desarrollos en política medioambiental no es unívoca. Para algunos, la tendencia actual a favor de combinar el enfoque regulativo tradicional con instrumentos de carácter económico-fiscal y politico (negociación y medidas voluntarias, básicamente), y el énfasis en mejorar la aplicación de la legislación en vigor, es positiva porque se dirige a afrontar el déficit de implementación que arrastra la política desde sus inicios. Por otro lado, también podria argumentarse que la combinación del principio de subsidiariedad con la extensión del voto por mayoría en el Consejo ${ }^{14}$, junto con la posibilidad de

\footnotetext{
${ }^{13}$ Siguiendo la decisión del Consejo Europeo en Amsterdam relativa a reforzar el componente medioambiental del texto, la Comisión ha acordado adoptar medidas internas que aseguren que las preocupaciones medioambientales son tomadas en cuenta en el proceso decisorio y, como reflejo de ello, ha designado responsables de integración medioambiental en cada Dirección General. Tambiés está examinando más detenidamente los efectos de los fondos europeos desde el punto de vista ecológico, y se ha comprometido a que el presupuesto comunitario sea más "verde" y a examinar los aspectos medioambientales de todas las nuevas propuestas que provengan de la propia Comisión.

14 Uno de los pocos temas relativos al medio ambiente, junto a la "fiscalidad ecológica" o la planificación hidrológica, que todavia quedaban sujetos al principio de decisión por unanimidad, como era la energía, pasaría a decidirse por mayoría cualificada según el proyecto de Constitución europea que se presentó a finales de mayo del 2003.
} 
que los Estados miembros puedan ir más allá de los estándares comunitarios (o de las prácticas de "mínimo común denominador"), podría favorecer una "Europa a la carta" o una "Europa de distintas velocidades" en el tema medioambiental. Esta posibilidad parece haberse visto reforzada con la tercera ampliación, que ha supuesto básicamente la incorporación de una sensibilidad ecológica especial a la Comunidad por parte de los países nórdicos, comprometidos con el tema medioambiental desde comienzos de los años setenta y precursores de esta política en diferentes foros internacionales. Este compromiso se demostró, por ejemplo, durante el proceso de adhesión, cuando el Primer Ministro sueco, Ingvar Carlsson, señaló la necesidad de mantener los estrictos estándares medioambientales existentes en su país. Asimismo, en el curso de las negociaciones se aceptaron, a petición de nuevo de Suecia, una serie de derogaciones que permitían la preeminencia de la legislación nacional sobre la comunitaria en este tema. Además, estos nuevos miembros de la UE reforzarán probablemente la posición de la troika dentro de la política medioambiental, no sólo por la similitud de los objetivos que persiguen, sino también por la arraigada tradición de cooperación que existe entre Suecia, Finlandia y Dinamarca.

Si se produjera esta diversificación del panorama medioambiental comunitario, ello no tendría por qué implicar un menor rigor en la dirección de la futura normativa, o en la aplicación de las normativas ya existentes. En este sentido, la

\begin{tabular}{|c|c|c|}
\hline $\begin{array}{l}\text { PRIMERA ETAPA (1972-86): } \\
\text { NEOF U N CIONA LIS MO } \\
\text { (spillover) }\end{array}$ & \begin{tabular}{|l|}
\multicolumn{3}{|l|}{ SEGUNDA ETAPA (1986-92): } \\
REALISMO (Estados) Y \\
NEOFUNCIONALISMO (lobbies \\
empresariales)
\end{tabular} & $\begin{array}{l}\text { TERCERA ETAPA (1992-): } \\
\text { GOVERNANCE } \\
\text { (nuevos actores estatales } \\
\text { y no estatales) y } \\
\text { CONSTITUCIONALISMO } \\
\text { (Tribunal de Justicia Europeo) }\end{array}$ \\
\hline $\begin{array}{l}1^{\circ} \text { PAM (1973-76) } \\
2^{\text {D }} \text { PAM (1977-80) } \\
3^{a} \text { PAM }(1981-84)\end{array}$ & $4^{n}$ PAM (1985-88) & $\begin{array}{l}5^{\mathrm{a}} \text { PAM (1992-99) } \\
6^{\circ} \text { PAM (2000-10) }\end{array}$ \\
\hline Acta Única Europea & Tratado de Maastricht & Tratado de Amsterdam \\
\hline $\begin{array}{l}\text { Política medioambiental } \\
\text { Enfoque predominantemente } \\
\text { correctivo (end-of-pipe) y } \\
\text { sectorial (centrado en los } \\
\text { efectos de contaminantes } \\
\text { especificos sobre medios } \\
\text { naturales concretos) } \\
\text { Política de aguas: directivas } 75 / \\
440,76 / 160,76 / 464,78 / 659, \\
79 / 923 \text { ) }\end{array}$ & $\begin{array}{l}\text { Política medioambiental } \\
\text { Enfoque preventivo (minimización } \\
\text { en el origen) e integrado (atención } \\
\text { a los efectos sinergéticos de la } \\
\text { contaminación) } \\
\text { Directivas de } 1991 \text { sobre aguas } \\
\text { residuales y nitratos }\end{array}$ & $\begin{array}{l}\text { Estrategia Europea de } \\
\text { Desarrollo Sostenible } \\
\text { Menor activismo regulativo } \\
\text { como combinación de } \\
\text { subsidiariedad, responsabilidad } \\
\text { compartida y enforcement. } \\
\text { Enfoque holistico } \\
\text { Directiva marco } 2000 / 60\end{array}$ \\
\hline
\end{tabular}


Comisión ya aseguró en 1995 que la aplicación del principio de subsidiariedad no conduciria a una reducción de los estándares medioambientales existentes. Esta afirmación se explica porque esta política ha servido de motor de la integración europea y disfruta, al mismo tiempo, del apoyo de los ciudadanos. Por ello, no es en absoluto probable que vaya a verse alterada sustancialmente por este principio, o por una interpretación "re-nacionalizadora" (en clave británica) del mismo. Si así fuera, la imagen de la UE podría experimentar un serio perjuicio porque la preocupación ecológica en Europa es alta: no hay más que recordar que, según los Eurobarómetros, la mayoria de los europeos piensa que la política medioambiental debe ser decidida por la UE y no por los gobiemos nacionales (Wurzel, en Lodge, 1994). El perjuicio, por otro lado, podría también afectar al propio estado del medio ambiente en la Comunidad porque las directivas comunitarias, a pesar de su deficiente cumplimiento, han supuesto un importantísimo esfuerzo de control y protección del mismo. Así, "en algunos Estados, la legisłación medioambiental de la UE representa más o menos la suma total de la legislación nacional, [e] incluso en aquéllos en los que éste no es el caso, las perspectivas han sido modificadas sustancialmente por la regulación comunitaria" (Blacksell, en Blacksell y Williams, 1994: p. 341).

La ampliación nórdica también es probable que refuerce las suspicacias (ya manifestadas por ciertos Estados miembros) en torno a determinadas actuaciones que benefician al Sur de Europa. El llamado plan "Mirada sobre el Sur", que promueve la cooperación económica, social y medioambiental entre los países mediterráneos, provocó las críticas de paises como Holanda y el Reino Unido, que consideraban que el dinero asignado al mismo era excesivo. Esta financiación ha sido rechazada, asimismo, por Alemania, que se opone a pagar más al presupuesto comunitario, y por los países nórdicos. Además, la futura integración de los países del Centro y Este de Europa aumentará, con toda probabilidad, la lucha en torno a la concesión de los fondos medioambientales por la catastrófica situación ecológica de los antiguos países comunistas ${ }^{15}$. Esta cuarta ampliación podria, asimismo, empujar en la dirección de redefinir la agenda de la UE de forma que los problemas específicamente mediterráneos volvieran a quedar relegados a un segundo término. No hay que olvidar, en este sentido, que la priorización del componente centro y nor-europeo de la política medioambiental parece haber vuelto con la entrada de los países nórdicos, a pesar de que la Comisión propusiera el área del Mediterráneo como ámbito prioritario para el año 2002. La entrada

\footnotetext{
${ }^{15} \mathrm{La}$ lucha en torno a estos fondos afectará más al de cohesión, por su mayor cuantía, que al fondo LIFE. Por otro lado, de prosperar la actual redacción del proyecto de Constitución europea, las decisiones sobre el fondo de cohesión pasarian a depender del voto por mayoria cualificada, con lo que España y los otros países receptores del mismo perderían su poder de veto.
} 
de nuevos paises antes del 2010 es para muchos el factor que más influirá en la política medioambiental en los próximos años, y ello podría explicar, en parte, el énfasis que se pone en la implementación y en el cumplimiento de la legislación existente, ligado a algo que podría denominarse "realismo medioambiental" y que se plasma en la siguiente declaración de Jean-Francois Verstrynge, de la DG $\mathrm{XI}$ : en los próximos diez años "la politica debe ser aproximada a la realidad", de forma que se produzca un cambio desde el pensamiento visionario que predominó durante la Cumbre de Rio a la puesta en práctica de las politicas (Bulletin del REC no 8/3).

Como consecuencia de todos estos cambios, la situación actual es cada vez más incierta, ya que la protección del medio ambiente se ha convertido en un complicado juego político debido a la reducción del margen de maniobra individual de los Estados miembros de la UE. La menor capacidad de éstos de recurrir al veto, y la necesidad de alcanzar mayorias cualificadas, conduce a que ahora proliferen las negociaciones tanto para establecer alianzas estables entre países que quieren promover propuestas de interés común, como para formar coaliciones de bloqueo, entre países que las rechazan. España, y el Sur de Europa en general, deberă pues seguir luchando para que sus específicas preocupaciones encuentren un hueco en la lista de prioridades comunitarias, mientras que se verá obligada a compartir fondos medioambientales con un mayor número de páses. El Sur de Europa podría intentar configurar un "régimen medioambiental internacional" parecido al que tienen los países nórdicos, ya que, si bien la identidad entre los sur-europeos no es absoluta (Grecia, por ejemplo, debido a los graves episodios de contaminación en Atenas, ha sido aliada de Dinamarca a la hora de exigir estándares de protección atmosférica más estrictos), sí se comparten determinados intereses y existen suficientes temas sobre los que organizar una cooperación estable entre los que destaca la defensa de la heterogeneidad de la biodiversidad europea, así como del muchas veces olvidado ecosistema mediterráneo (Aguilar, 1997a).

De todos modos, y más allá de este sistema de alianzas y coaliciones de bloqueo, el programa de DS a nivel comunitario, que subsume, de alguna forma, la siempre polémica política de medio ambiente en una estrategia global de crecimiento económico de calidad, con contenido tanto social como medioambiental, parece haber concitado un apoyo generalizado entre los distintos países europeos, al menos a nivel retórico (prueba de ello son las entusiastas declaraciones que se han producido tras determinadas cumbres del Consejo Europeo). Este apoyo se explica, principalmente, por dos rasgos del DS. Por un lado, la supuesta compatibilidad que preconiza entre crecimiento económico, protección del medio ambiente y reducción de las desigualdades sociales, permite ocultar la naturaleza política (en términos de decisiones que afectan al juego politico tal y como ha sido tradicionalmente definido: quién gana/pierde qué, cómo y cuándo), y lógicamente conflictiva, de las estrategias de sostenibilidad; y, por otro lado, su relativa imprecisión, en el sentido de que el DS significa cosas distintas según 
el gobierno, partido, o agente socio-económico en cuestión, hace posible que se estén elaborando actualmente estrategias de sostenibilidad absolutamente dispares que recogen, en ocasiones, objetivos contradictorios, lo cual tiene indudablemente relación tanto con la diversidad de trayectorias que el concepto admite, como con la gran inexperiencia existente en cuanto a la aplicación con éxito de políticas sostenibles se refiere.

\section{LAS CLAVES DEL ÉXITO DE LA ESTRATEGIA DE DESARROLLO SOSTENIBLE EN LA UNIÓN EUROPEA}

Ya en el Plan de Acción de Estocolmo, que dimanaba de la Conferencia sobre Medio Ambiente y Desarrollo celebrada en dicha ciửad en 1972, se señalaba que la gestión medioambiental debía facilitar una planificación comprehensiva que tuviera en cuenta los efectos no deseados de las actividades humanas y que protegiera el medio ambiente para las generaciones presentes y futuras. Sin embargo, sólo a partir de 1987, y gracias al trabajo de la Comisión sobre Medio Ambiente y Desarrollo, de Naciones Unidas, se universaliza el concepto de DS, definido como "el desarrollo que satisface las necesidades del presente sin comprometer la capacidad de las generaciones futuras de satisfacer sus propias necesidades". Este trabajo, recogido en el Informe Brundtland, defendia la tesis de que el crecimiento económico y la protección del medio ambiente son compatibles siempre y cuando el primero sea reformulado para atender las necesidades del segundo. La UE, como ya se vió anteriormente, ha acogido sin reservas la noción de DS, tanto en las textos que reforman sus tratados fundacionales (principalmente en los Tratados de Maastricht y Amsterdam), en sus últimos PAM, asi como en diversas declaraciones por parte de las distintas instancias que la componen. $\mathrm{La}$ "fórmula mágica" de la compatibilidad entre crecimiento material y defensa del entomo físico explica, en gran medida, el éxito político del DS en el seno de la UE, a pesar de que, junto a su imprecisión o acepción polisémica, tal vez uno de los mayores problemas de este concepto sea que se ha pasado de una concepción antagónica a otra acríticamente armónica de ambos. Más que hablar de una armonia, que ahora se da por supuesta, lo que habría que resaltar es el elemento de interdependencia (o de sinergias) que subyace en el concepto. La interdependencia permite comprender complejos problemas, como por ejemplo el de la pobreza endémica en los paises en vías de desarrollo, tanto como resultado de la degradación del entomo como en su vertiente de agente causante de este mismo deterioro ecológico. Esta interdependencia, además, está íntimamente vinculada a problemas de governance global, o a la tensión que existe entre la percepción de una interrelación económica y medioambiental crecientes, y el énfasis que ponen los Estados, y determinadas comunidades locales y grupos étnicos, en la independencia o autodeterminación políticas. Un ejemplo puede ayudar a elucidar 


\section{RIS}

esta tensión: el gobierno norteamericano y las organizaciones ecologistas internacionales describen los bosques tropicales brasileños como "herencia común de la humanidad", poniendo el acento en la interdependencia ecológica, mientras que, cuando el anterior presidente de este país, Sarney, señalaba que preferia "un desierto brasileño a un bosque internacional", el énfasis se colocaba en la soberanía e independencia nacionales como bases de la gestión del problema amazónico. De hecho, el paso de los mecanismos regulativos a los de mercado a la hora de encarar problemas que, como el cambio climático, caen dentro del dilema conocido como "tragedia de los comunes", refleja un paso atrás en la noción de interdependencia y un paso adelante en la afirmación del valor de la independencia nacional o autonomia individual y grupal (Rayner, 1994) ${ }^{16}$.

Otra de las razones del triunfo del DS estriba en el enfoque antropocentrista que subyace en lo que podría denominarse la acepción mayoritariamente compartida del concepto. El enfoque político que subyace en la sostenibilidad se sitúa cerca de la denominada estrategia de gestión, o management approach. Esta estrategia es la heredera del enfoque de conservación de recursos defendido por Pinchot (primer director del Servicio Nacional de Bosques de Estados Unidos), cuyo principal objetivo era asegurar una provisión sostenible de materia prima para consumo del hombre. La gestión racional, orientada hacia la planificación a medio y largo plazo y centrada en la estabilidad y continuidad, se basa principalmente en la regulación. La regulación, entendida como "la legislación o [conjunto de] reglas, apoyadas en sanciones, que tienden a limitar la discrecionalidad de agentes públicos y privados" (Rayner, 1994: 8), sigue siendo, tal y como se vio anteriormente, el pilar básico de la política medioambiental europea, por mucho que esté siendo complementada por instrumentos económico-fiscales o voluntarios, que ponen el énfasis en la capacidad auto-regulativa de los individuos y grupos socio-económicos. Aunque el DS intente una atemperación del enfoque antropocentrista que subyace en la estrategia de gestión, sigue resaltando la necesidad de planificación a largo plazo del crecimiento económico de forma que éste se "sostenga" en el tiempo gracias a la reducción de las externalidades sobre el medio ambiente y a la aminoración de las desigualdades sociales ${ }^{17}$.

\footnotetext{
${ }^{16}$ La tragedia de los comunes ha sido utilizada políticamente por parte de aquellos intereses que defienden la privatización de recursos colectivos, muchas veces en países en vias de desarrollo, ocultándose, así, que el verdadero problema radica en aquella propiedad comunal que es de acceso abierto o universal, y no en la comunalidad de la propiedad en si (Rayner, 1994).

"No obstante, existen otros modos, menos antropocéntricos, de entender el DS, tal y como muestra la construcción del mismo a través de la metáfora de una escalera, que iría desde el "modelo ideal" de DS, al "desarrollista" (treadmill) de Baker et al. (1997).
} 
El compromiso de la UE con respecto al DS parece ser perseguido con más ahinco, sin embargo, en el plano internacional que en el propiamente europeo. Debido, entre otras razones, a que los ciudadanos europeos están a favor de que la UE juegue un papel más importante en la protección del medio ambiente a nivel internacional, tanto en la Conferencia sobre Medio Ambiente y Desarrollo de las Naciones Unidas, celebrada en Río de Janeiro en $1992^{18}$, como en la Cumbre de Johanesburgo del 2002, la Comunidad ha intentado, no obstante sin éxito, hacer prevalecer sus tesis vinculantes en relación al DS, frente a las medidas basadas en la voluntariedad y en las declaraciones de principios. Este ejercicio de presión de la UE, que buscaba reducir el aspecto retórico-simbólico de las resoluciones para favorecer el impositivo-regulativo, encuentra un ejemplo en la finalmente rechazada propuesta europea según la cual el $15 \%$ de la energía primaria del mundo debía proceder en el año 2010 de fuentes renovables ${ }^{19}$. En consecuencia, de los tres "regímenes internacionales" que han podido identificarse en la Cumbre (el europeo, el de los paises en vías de desarrollo, o G-77, y el liderado por Estados Unidos, que reunía a Japón, Canadá, Nueva Zelanda, y Rusia, entre otros), la UE ha sido el que mayor número de iniciativas ambiciosas ha propuesto.

Esta mayor ambición no debe confundirse con una total adhesión hacia el programa de la sostenibilidad por parte de los quince Estados miembros de la Comunidad, ya que el compromiso en tomo a éste depende, en gran medida, del país que asume la presidencia semi-anual del Consejo Europeo. "Ello se ve claramente en el caso de la Cumbre de Barcelona, que, anunciada por el director de la Agencia Europea de Medio Ambiente como una ocasión histórica para que las exigencias medioambientales fueran finalmente integradas, en condiciones de igualdad, en la impresionante agenda socio-económica que el Consejo aprobó en Lisboa en el año 2000, terminó con un resultado decepcionante, ya que los temas de DS, que inicialmente aparecieron como objetivos de la Presidencia española, terminaron siendo relegados a un segundo plano a favor de un enfoque centrado

\footnotetext{
${ }^{1}$ En Río, tal vez la propuesta europea más ambiciosa fue la de aplicar un impuesto ecológico para reducir las emisiones de dióxido de carbono, siempre y cuando se contara con el apoyo de los Estados Unidos y Japón. Los resultados de esta conferencia fueron las convenciones sobre cambio climático, biodiversidad, y gestión de recursos forestales, la Agenda 21, y la Declaración de Río. Todos ellos están ya incidiendo, de alguna forma, en el curso de la política comunitaria: la Agenda 21, por ejemplo, está reflejada en el $5^{\circ} \mathrm{PAM}$, mientras que los Estados miembros deben elaborar planes para aplicar los convenios sobre biodiversidad y cambio climático, y realizar propuestas sobre gestión de los bosques.

${ }^{19}$ Esta propuesta ha terminado convirtiéndose en una iniciativa voluntaria (con un compromiso en cuanto a fechas y objetivos asi como un sistema de fiscalización de cumplimiento de los mismos) a la que se han adherido distintos paises.
} 
RIS

GFYISS INTERHACIOKAL DE SOCIOLOCIL

N 35, Mayo-Agosta, 20103

en la competitividad económica ${ }^{20}(. .$.$) . Lógicamente, por lo tanto, los avances que$ a nivel comunitario se produzcan en el (...) DS dependerán en gran medida de la "sensibilidad ecológica" de los distintos países, lo cual da lugar a un movimiento pendular que oscila entre el optimismo (en cumbres como las de Cardiff de 1998, o Gotenburgo de 2001, en las que la sostenibilidad ocupó una posición clave) y el pesimismo (caso de la cumbre de Barcelona del 2002, en la que el tema pasó desapercibido)" (Aguilar, 2004: 10-11).

Los diferentes Estados miembros de la UE encuentran en los rasgos de armonía e imprecisión del concepto de DS la excusa perfecta para elaborar estrategias nacionales que, ajustándose en mayor o menor medida a las preferencias del electorado y a los intereses prioritarios del país (tal y como ambos son definidos por los distintos gobiernos), se caracterizan por su gran heterogeneidad de contenido, predominando, en muchas de ellas, la indefinición en cuanto a objetivos, instrumentos a aplicar y plazos de cumplimiento. En una investigación comparada a nivel de la OCDE, por ejemplo, se comprobó que, aunque dentro del amplio abanico de planes medioambientales nacionales y estrategias de sostenibilidad que se han llevado a cabo por muy distintos países, los contenidos oscilan entre los de tipo genérico (como el Reino Unido, Japón, Finlandia y Austria), y aquellos otros que abarcan metas especificas junto a marcos temporales concretos y medidas para la aplicación del DS (los Países Bajos, Corea, Suecia y Noruega), situándose algunos países como Canadá y Alemania en una categoria intermedia, la mayoría de ellos se aproxima al primer grupo (Jänicke y Jörgens, 2000). Aunque es cierto que la heterogeneidad de estrategias y orientaciones a la hora de aplicar la politica medioambiental europea por parte de los Estados miembros ha sido una constante de este área de gestión desde sus comienzos en los años setenta, y ha llevado a algunos autores a afirmar "una revitalización dentro de la UE de las identidades o estilos nacionales utilizados por los Estados miembros en la formulación de políticas públicas" (Buller y Hoggart, 1998: 154), esta diversidad es aún mayor en el caso del DS. Coexisten, por ello, planteamientos contradictorios e incluso antagónicos a la hora de resolver problemas similares, algo que puede explicarse en gran medida por la ambigüedad, la imprecisión y el "elemento idiosincrático" (o de path-dependence) que acompañan al DS. No deja de resultar en consecuencia paradójico que, a nivel internacional, la UE lidere propuestas de sostenibilidad concretas y vinculantes, mientras que, a nivel europeo, no otorgue obligatoriedad jurídica a las estrategias nacionales de DS que están llevando a cabo sus Estados

${ }^{20}$ El DS fue contemplado como uno de los objetivos, del gobierno del PP cuando asumí́ la Presidencia del Consejo Europeo a comienzos del año 2002, pero las referencias al mismo fueron eliminadas en posteriores documentos a favor de temas como la lucha contra el terrorismo internacional, el desarrollo de la política exterior europea, o la liberalización del mercado eléctrico (Aguilar, 2003a). 
miembros y les permita, al mismo tiempo, adoptar documentos dispares e imprecisos en cuanto a la definición de objetivos, medidas y horizontes temporales de ejecución.

En el nivel nacional, por último, la voluntad política de llevar a cabo políticas de sostenibilidad debe ir acompañada por el necesario consenso interpartidista e institucional (entre las distintas administraciones) que permita su cumplimiento con independencia de los resultados de los comicios electorales. Este consenso debe sustentarse, asimismo, en un proceso de consulta y debate con los grupos de interés (principalmente, empresarios, sindicatos, ecologistas y expertos), de forma que éstos contribuyan a mejorar la estrategia de sostenibilidad y se comprometan a facilitar su implementación. Estos apoyos, tanto partidistas como institucionales y sociales, forman parte de la etapa de legitimación que el policy analysis recoge como elemento fundamental dentro del proceso de formación de las políticas públicas, pero que, desgraciadamente, los responsables politicos tienden a olvidar escudándose en la legitimidad democrática que les proporcionan las urnas. El DS se presenta, así, como una magnifica oportuniđad para profundizar en la democracia sustantiva y para ensayar nuevos mecanismos de participación. El reto político, así como también administrativo-institucional, de la sostenibilidad puede resumirse en la necesidad de acometer lo que actualmente se denomina new governance, entendida como una mejor asignación de responsabilidades $o$ rendimiento de cuentas de los responsables políticos (accountability), mayores facilidades en el acceso a la información y la puesta en práctica de mecanismos de participación social, la necesidad de superar inercias político-administrativas que consagran la autonomía departamental, la sectorialización de las políticas, el incrementalismo presupuestario y la descoordinación dentro y entre las administraciones, y la necesidad de legislar menos y aplicar mejor las políticas aprobadas (Aguilar, 2004). Asimismo, la necesidad de contar con un liderazgo político de calidad a nivel Iocal, regional y, sobre todo, nacional y comunitario, es innegable: un liderazgo comprometido sin ambages con el DS, que busca el consenso interpartidista, institucional y social en políticas que superan con mucho el corto ciclo electoral. Este es el reto del new governance, que está lejos de haberse plasmado en prácticas concretas y que adolece, además, de una total disparidad de programas y criterios, lo cual puede provocar una situación de impasse con respecto a la promoción del DS en general, y de la política medioambiental en particular.

\section{CONCLUSIONES}

En la evolución de la politica medioambiental de la UE se constata la progresiva implantación de la sostenibilidad, como principio que aspira a hacer compatibles el crecimiento económico, la protección medioambiental y la cohesión 
social, abandonándose enfoques anteriores que ponían el énfasis en la primacia del mercado común y regulaban el tema del medio ambiente únicamente para evitar distorsiones económico-comerciales, o que llegaron, de forma inversa, a considerar el freno del deterioro ecológico un objetivo primordial que justificaba determinadas restricciones a la libre circulación de mercancías.

En nuestros días, por lo tanto, la política medioambiental se ubica en un punto intermedio, buscando un equilibrio entre principios que ya no se consideran incompatibles, puesto que, más bien al contrario, se necesitan recíprocamente: el crecimiento económico sólo podrá mantenerse en el tiempo y ser aceptado por los ciudadanos si, de forma simultánea, reduce las desigualdades sociales y protege el entorno físico. El problema de la concepción ammónica del DS es doble: por un lado, esta armonía es falsa, ya que relativiza la naturaleza política de las estrategias de sostenibilidad, en el sentido de que las propuestas que éstas incorporan generarán indudablemente ganadores y perdedores -los ganadores serian, hipotéticamente, las generaciones futuras que se beneficiarán de un medio ambiente mejor conservado y de una sociedad menos desigual, mientras que los perdedores serían aquellos grupos productivos que tienen que asumir los costes, en el presente, de las medidas que conducen al DS. Por otro lado, la compatibilidad que ahora se preconiza se sitúa en el plano retórico, pues no se ha plasmado aún, en la mayor parte de los países, en politicas concretas (con instrumentos, objetivos, plazos y mecanismos de evaluación específicos). La sostenibilidad sólo se puede conseguir revirtiendo, o encauzando, determinadas tendencias politicas, productivas, demográficas y sociales desde una perspectiva de diálogo institucional (entre las distintas administraciones), político (entre los partidos) y social (entre los responsables políticos y los target groups, básicamente), sin olvidar nunca que la responsabilidad del gobieno (sea éste nacional, regional o local) es fundamental a la hora de impulsar y coordinar este proceso.

\section{REFERENCIAS BIBLIOGRÁFICAS}

AGUILAR, S. (1997a), “Abandoning a Laggard Role?: New Strategies in Spanish Environmental Policy", en D. Liefferink y M. Skou (eds.), The Innovation of EU Environmental Policy. Copenhague, Scandinavian University Press.

\footnotetext{
(1997b), El reto del medio ambiente. Confictos e intereses en la politica medioambiental europea $a_{\star}$ Madrid, Alianza Universidad, Madrid.

(1997c), "Subsidiarity, Shared Responsibility, and Environmental Policy in Spain", en U. Collier, J. Golub y A. Kreher (eds.), Subsidiarity and Shared Resposibility: New Challenges for EU Environmental Policy, Baden, Nomos Verlagsgesellschaft.
}

(1998), "Las consecuencias de la integración europea en la política medioambiental española", en I. Llamazares y F. Reinares (eds.), Aspectos politicos y sociales de la integración europea, 
Valencia, Tirant Lo Blanch.

(2003), "El principio de integración medioambiental dentro de la UE: la imbricación entre integración y desarrollo sostenible", PAPERS, no 70 (en prensa).

(2004), "Sustainability is Cool: Rhetorical Participatory Discourse in the Spanish Strategy for Sustainable Development", en W. Lafferty(ed), Sustainable Development; Adjusting Form to Function. (De próxima aparición en Edward Elgar).

ARP, A. (1992), "The European Parliament in European Community Environmental Policy", EUI WP n ${ }^{\circ} 92 / 13$, Flotencia.

BAKER, S., M. KOUSIS, D. RICHARDSON y S. YOUNG (1997), The Politics of Sustainable Development, Londres, Routledge.

BENNET, G. et al. (1989), The Internal Market and Environmental Policy in the Federal Republik of Germany and The Netherlands, Arnhem (NL), Institute for European Environmental Policy.

BLACKSELL, M. y A.M. WILLIAMS (1994), The European Challenge ${ }_{\mathrm{a}}$ Oxford, Oxford University Press.

BULLER, H. y K. HOGGART (1998), "Pluralidad e implementación de políticas de medio ambiente en la Unión Europea”, Revista Internacional de Sociologia, n 19 y 20, pp. 153-179.

CELLULE DE PROSPECTIVE (CDP) (1991), Mandate on Envinonment and Economic Development, Bruselas, Mimeo.

GRANT, W., D. MATTHEWS y P. NEWELL (2000), The Effectiveness of European Union Envinonmental Policy, Londres, MacMillan.

JÄNICKE, M. y H. JÖRGENS (2000), "Strategic Environmental Planning and Uncertainty: A CrossNational Comparison of Green Plans in Industrialized Countries", Policy Studies Journal, vol. $28, n^{0} 3$.

KOPPEN, I.J. (1992), "The Role of the European Court of Justice in the Development of the European Community Environmental Policy", EUI WP N 92/18, Florencia.

KRÄMER, L. (1988), "Einheittiche Europäische Akte und Umweltschutz: Überlegungen zu einigen neuen Bestimmungen im Gemeinschaftsrecht", en H.W. Rengeling (coord.), Europöisches Umweltrecht und europäische Umweltpolitik, Berlin, Carl Heymanns.

LIBERATORE, A. (1993), "Beyond the Earth Summit: the European Community towards Sustainability?", EUI Working Paper EPU N 93/5, Florencia.

LODGE, J. (1994), The European Community and the Challenge of the Furure, Londres, Frances Pinter.

LYNCH, P., N. NEUWAHL y W. REES (eds.) (2000), Reforming the European Union, Essex, Pearson. 
RIS

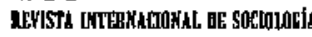

N' 35, Hayo-Agosto, 20013

SISANA ACUIILAR FERNANDEZ

MIDDLEMAS, K. (1995), Orchesfrating Europe, Londres, Fontana Press.

PANIAGUA, A. y E. MOYANO (1998), "Medio ambiente, desarrollo sostenible y escalas de sustentabilidad", $R E I S, \mathrm{n}^{\circ} 83$, pp. 151-175.

RAYNER, S. (1994), "Govemance and the Global Commons", The Centre for the Study of Global Governance, London School of Economics, Discussion Paper 8.

SBRAGIA, A. (1993), "EC Environmental Policy: Atypical Ambitions and Typical Problerns?", en A.W. Cafruny y G.G. Rosenthal, The State of the European Community, Colorado, Longman.

SNYDER, F. (1999), Globalisation and Europeanisation as Friends and Rivals; European Union Law in Global Economic Networks, EUI Working Paper Law n ${ }^{\circ}$ 99/8, Florencia

WEBER, B. (1988), "Die ungeliebte Gemeinschaft -uber den Umgang mit europäischer Umweltpolitik", en L. Gundling y B. Weber, Dicke Luft in Europa, Heidelberg, C.F. Müller Juristischer Verlag. 